\title{
Hypertension Knowledge, Attitude, and Practice in Adult Hypertensive Patients at a Tertiary Care Hospital in Sri Lanka
}

\author{
Udaya Ralapanawa $\mathbb{D}^{1},{ }^{1}$ Kameera Bopeththa, ${ }^{2}$ Noorika Wickramasurendra, ${ }^{1}$ \\ and Sampath Tennakoon ${ }^{3}$ \\ ${ }^{1}$ Department of Medicine, University of Peradeniya, Peradeniya, Sri Lanka \\ ${ }^{2}$ Emergency Medicine, Teaching Hospital, Peradeniya, Sri Lanka \\ ${ }^{3}$ Community Medicine, Faculty of Medicine, University of Peradeniya, Peradeniya, Sri Lanka
}

Correspondence should be addressed to Udaya Ralapanawa; udayapralapanawa@yahoo.com

Received 17 May 2020; Revised 3 August 2020; Accepted 17 September 2020; Published 21 October 2020

Academic Editor: Tomohiro Katsuya

Copyright () 2020 Udaya Ralapanawa et al. This is an open access article distributed under the Creative Commons Attribution License, which permits unrestricted use, distribution, and reproduction in any medium, provided the original work is properly cited.

\begin{abstract}
Objective. Hypertension (HTN) remains a major risk factor for cardiovascular diseases globally. Despite considerable improvement in increasing awareness, treatment, and control of HTN, undiagnosed and uncontrolled HTN remains a major public health challenge. Our focus was on studying the knowledge, attitude, and practice regarding HTN in adult hypertensive patients at a tertiary care hospital in Sri Lanka. Methodology. A descriptive study on knowledge, attitude, and practice of hypertensive patients on antihypertensive medications attending the hypertensive clinic was carried out from January 2016 to June 2016 at THP. Results. The study was on a total of 371 hypertensive patients comprising 253 (68.2\%) females and 118 (31.8\%) males. Among the total participants, 12 (3.2\%), all females, had never been to school. About half of them (47.7\%) had not even reached GCE (ordinary level). More than two-thirds (77\%) of the study population were aware of the complications of HTN as they were informed by a health care team member. About $74 \%$ of them were taking all their prescribed medications. Almost all (95\%) patients had checked their blood pressure (BP) during the previous 12 months, and almost the same percentage had visited their doctor for BP checkups every 1-3 months. Conclusion. Our patients were well aware of the importance of regular follow-ups and also knowledgeable about the complications related to HTN. Almost $75 \%$ of the patients had optimum drug compliance. It was revealed that forgetfulness was the frequent cause for poor drug compliance.
\end{abstract}

\section{Introduction}

HTN remains a major risk factor for cardiovascular diseases around the world [1-4]. Globally, cardiovascular disease accounts for approximately 17 million deaths a year, nearly one-third of the total. Of these, complications of HTN account for 9.4 million deaths worldwide annually [5]. Despite considerable improvement in increasing the awareness, treatment, and control of HTN, undiagnosed and uncontrolled HTN remains a public health challenge [6-8]. It disproportionately affects populations in low- and middleincome countries, with consequences such as stroke, kidney failure, peripheral vascular disease, and premature disability [9-11]. Similarly, HTN is frequently seen among hospital patients in the Republic of Sri Lanka. However, the prevalence of HTN in Sri Lanka is not known $[12,13]$.

HTN presents a major area of intervention because it is a frequently occurring condition that is amenable to control through both nonpharmacological lifestyle factors and pharmacological treatment [14]. While antihypertensive medications have been used for blood pressure control, there has been increasing emphasis on the prevention and treatment of HTN by nonpharmacological means termed lifestyle modifications [15]. The recommended lifestyle measures that have been shown to be capable of reducing blood pressure include (i) salt restriction, (ii) moderation of alcohol consumption, (iii) high consumption of vegetables and fruits and low-fat and other types of diet, (iv) weight 
reduction and maintenance, and (v) regular physical exercise. Hypertensive patients irrespective of their stage or grade should be motivated to adopt these measures. Motivating patients to implement lifestyle changes is probably one of the most difficult aspects of managing HTN [16]. A KAP survey means knowledge, attitude, and practice. KAP questions tend to reveal not only characteristic traits in knowledge, attitude, and behaviors about health but also the idea that each person has of the disease. These factors are often the source of misunderstandings. The obstacle to change may be lack of knowledge [17]. Recent reports have suggested that HTN knowledge is related to blood pressure control [18]. The importance of HTN awareness and knowledge and the potential impact of BP education programs have been reported on recently [19-21]. Although the outcome of a KAP study seems simple, the results of the study can have a huge impact on the local community. As the KAP study explores what is known and what is done in relation to a health care-related objective which is about hypertension in this study, the results will reveal the baseline information of the community and may reveal the misconceptions or misbehaviors in relation to practice of hypertension. It is very important to identify these facts as these directly influence the future health care-related interventions. Moreover, results of the KAP study establish reference values on various health care parameters for use in future assessments. Also, aspects assessed by the KAP study are not uniform to the entire communities. Therefore, results of the KAP study derived based on Western data cannot be applied to our local community. In summary, it is justifiable to conduct a study on assessment of knowledge, attitude, and practice in relation to hypertension in a local community as this will reveal important unknown data on hypertension to guide future research studies and health-related interventions.

This study was conducted to study the knowledge, attitude, and practice of HTN in adult hypertensive patients at Teaching Hospital Peradeniya (THP). This is aimed at the potential new development of interventional strategies to reduce HTN-related morbidity and mortality.

\section{Materials and Methods}

2.1. Study Design and Site. A descriptive study on knowledge, attitude, and practice of hypertensive patients on antihypertensive medications attending the hypertensive clinic was carried out from January 2016 to June 2016 at THP. This is one of the largest tertiary care hospitals in the central province of Sri Lanka. The approval for this study was obtained from the Ethical Review Committee of the Faculty of Medicine, Peradeniya, and the administration of the hospital.

2.2. Inclusion and Exclusion Criteria. Patients who were on antihypertensive medications for more than six months with uninterrupted clinic attendance, with or without comorbidities of both sexes, were included in the study. Excluded from the study were pregnant patients.
2.3. Sample Size and Sampling. Following application of inclusion and exclusion criteria, a total of 371 patients representing all patients attending the clinic during the study period were enrolled in the study.

2.4. Data Collection. The study was conducted within the hypertensive clinic premises. A well-structured, face-to-face, interviewer-administered questionnaire was administered in the local language by four well-trained health care professionals who had previous experience in conducting such studies. Comprehensive sociodemographic information of the participants was gathered at the beginning of the study. There were 22 questions assessing knowledge, attitude, and practice of hypertensive patients. The questionnaire was prepared in the English language and translated into the local language and finalized after pretesting.

2.5. Variables and the Method of Verification. Knowledge and attitude questions were posed. Three fixed answering options, "yes," "no" followed by "uncertain," were offered. Other close-ended questions especially related to questions assessing practice were organized to offer three to seven response options. If a participant had ever smoked, then they were categorized as smokers, and options were "yes" or "never." Similar options were offered to those who had imbibed alcohol as well.

2.6. Statistical Analysis. Data were entered in an electronic format and analyzed using SPSS 16 package. A monovariate analysis was performed to describe the study sample, and chi-square and difference between means were used to explore associations between variables. A $p$ value less than 0.001 was considered statistically significant.

\section{Results}

Baseline sociodemographic characteristics of the patients participated in the study are depicted in Table 1 . There were a total of 371 hypertensive patients, and among them, 253 $(68.2 \%)$ were females and $118(31.8 \%)$ were males. The median age of male participants was 65 years and that of female participants was 64 years. The total study population was composed of $91.9 \%$ Sinhalese, 2.2\% Tamils, 5.7\% Muslims, and $0.5 \%$ of other ethnic groups. Of the participants, there were 91.9\% Buddhists, 0.8\% Hindus, 5.7\% Muslims, $1.3 \%$ Christians, and $0.3 \%$ other religions. Among the total participants, 12 (3.2\%) had never gone to school, and all were females. About half of them (47.7\%) had not studied up to the GCE (ordinary level). Of these, $177 \mathrm{pa}-$ tients, a majority $(72.9 \%)$ were females. Only $14(3.8 \%)$ patients had stepped beyond the advanced level and showed equal gender distribution. There was a statistically significant association between gender and level of education $(p=0.013)$. Of the total participants, $171(46.1 \%)$ were unemployed, and of them, $99.4 \%$ were females. There were 83 (22.4\%) unskilled workers, 47 (12.7\%) skilled workers, 25 (6.7\%) business workers, and 45 (12.1\%) professionals. Of 
the professionals, $53.3 \%$ were females. There was a statistically significant association between gender and category of occupation $(p \leq 0.001)$. Approximately $50 \%$ of patients had a sufficient household monthly income of more than 12,000 rupees. Only $3.5 \%$ of participants had incomes less than 3000 rupees. $75 \%$ of the patients had never smoked, and $90 \%$ of the patients were females. Similarly, 278 (75\%) had never ingested alcohol, and out of them, $90 \%$ were females. There was a statistically significant association of gender with smoking and alcohol consumption $(p \leq 0.001)$.

According to Table 2, more than half of our study population (60\%) had chronic HTN (more than 5 years). Fifty percent reported that they were first diagnosed as having HTN in a tertiary care hospital, and only $6.5 \%$ were diagnosed in a primary care centre. Almost all patients (94\%) were taking antihypertensive medications to control their HTN. More than two-thirds (77\%) of the study population knew of the complications of HTN and were informed by a health care team member. A significant percentage (77\%) of patients expressed that strokes were related to HTN. Regarding complications related to HTN, 35\% had cardiovascular complications, $5 \%$ percent had suffered from strokes, and 3\% percent had renal disease. When questioned regarding their family history of $\mathrm{HTN}, 58 \%$ of patients recalled positive family histories. Inquiries regarding lifestyle changes advised by a doctor to lower BP and blood cholesterol level revealed that a considerable percentage (65\%) had received such advice. Questions about blood cholesterol level showed that $55 \%$ of patients were on medications to lower blood cholesterol levels, and the same percentage of patients had checked their cholesterol levels during the previous 12 months. Inquiries about drug compliance revealed that $74 \%$ were taking all prescribed medications, but detailed questioning did not reveal specific reason(s). We asked patients about the follow-up on their HTN. Almost all (95\%) patients had checked their BP within the last 12 months, and almost the same percentage of patients had seen their doctor for BP checkup every 1-3 months. Fifty-eight patients had attended our health care institution, and 25\% had attended a nearby primary or secondary health care facility for routine follow-up to check their BP.

\section{Discussion}

We conducted a descriptive study to assess the current status of knowledge, attitude, and practice about HTN in adult hypertensive patients at THP. Although globally men have a slightly higher prevalence of HTN than women, women had a higher prevalence of HTN in our study [22]. The literacy rate is also higher in men globally, and our study also showed the same results [23]. Our studies have found that, of $50-60 \%$ of the study population, the place of the first diagnosis of HTN and place of regular follow-up was a tertiary care hospital. Uncomplicated hypertensive patients can be easily managed at primary or secondary care hospitals. Reasons for bypassing these levels may be due to developing demand for specialized care and or unavailability of proper referral systems [24]. Therefore, attention must be paid when implementing measures to improve health infrastructure in
TABLE 1: Baseline sociodemographic characteristics of the patients participated in the study.

\begin{tabular}{|c|c|c|}
\hline \multirow{2}{*}{$\begin{array}{l}\text { Baseline sociodemographic } \\
\text { Characteristics }\end{array}$} & \multicolumn{2}{|c|}{ Characteristics $(N=371)$} \\
\hline & Category & $N(\%)$ \\
\hline \multirow{2}{*}{ Sex } & Female & $253(68.2)$ \\
\hline & Male & $118(31.8)$ \\
\hline \multirow{4}{*}{ Ethnicity } & Sinhala & $340(91.6)$ \\
\hline & Tamil & $8(2.2)$ \\
\hline & Moor & $21(5.7)$ \\
\hline & Others & $2(0.5)$ \\
\hline \multirow{5}{*}{ Religion } & Buddhist & $341(91.9)$ \\
\hline & Hindu & $3(0.8)$ \\
\hline & Islam & $21(5.7)$ \\
\hline & Christian & $5(1.3)$ \\
\hline & Others & $1(0.3)$ \\
\hline \multirow{6}{*}{ Level of education } & No school & $12(3.2)$ \\
\hline & $<$ ordinary level & $177(47.7)$ \\
\hline & Ordinary level & $103(27.8)$ \\
\hline & $\mathrm{O} / \mathrm{L}-\mathrm{A} / \mathrm{L}$ & $4(1.1)$ \\
\hline & Advanced level & $61(16.4)$ \\
\hline & Beyond A/L & $14(3.8)$ \\
\hline \multirow{5}{*}{ Occupation } & House work & $171(46.1)$ \\
\hline & Unskilled & $83(22.4)$ \\
\hline & Skilled & $47(12.70)$ \\
\hline & Business & $25(6.7)$ \\
\hline & Professional & $45(12.1)$ \\
\hline \multirow{5}{*}{ Monthly income (in rupees) } & $<3000$ & $13(3.5)$ \\
\hline & $3000-6000$ & $19(5.1)$ \\
\hline & $6000-12000$ & $49(13.2)$ \\
\hline & $>12000$ & $185(49.9)$ \\
\hline & Not answered & $104(28)$ \\
\hline \multirow{2}{*}{ Ever smoked } & Yes & $91(25)$ \\
\hline & Never & $280(75)$ \\
\hline \multirow{2}{*}{ Ever took alcohol } & Yes & $93(25)$ \\
\hline & Never & $278(75)$ \\
\hline
\end{tabular}

the future. Our patients were well aware of the importance of regular follow-up and knowledgeable about the complications related to HTN because $95 \%$ of patients had checked their BP within the last 12 months with regular 1-3 monthly interval checkups, and over $75 \%$ of the patients were aware of the complications related to HTN. We asked patients about advice received from a doctor to change their way of life to lower BP. Almost $70 \%$ of patients reported that a doctor had indeed explained the matter to them. To achieve the maximum coverage of patients, we may have to use other sources to disseminate HTN information including mass media as it had been identified as a major source of information [25]. Fifty-three percent of the study population had blood relatives with HTN. This may signify the genetic predisposition of HTN. For early recognition of HTN, we may need to have national level awareness enhancing programs to recognize the at-risk group. To ascertain their attitude towards adherence to taking all prescribed medications, we posed questions about their drug compliance. Almost $75 \%$ of patients had optimum drug compliance. Further exploration for reasons of poor drug compliance revealed forgetfulness to be the most frequent cause. Forgetfulness may not imply patient's poor attitude towards the 
TABLE 2: KAP related to hypertension.

\begin{tabular}{|c|c|}
\hline & $N(\%)$ \\
\hline $\begin{array}{l}\text { How did you come to know about y } \\
\text { In a routine medical clinic } \\
\text { Screening programme } \\
\text { Emergency service } \\
\text { Others } \\
\text { I do not know }\end{array}$ & $\begin{array}{l}\text { n? } \\
66(17.8) \\
29(7.8) \\
70(19) \\
192(52) \\
1(0.3)\end{array}$ \\
\hline $\begin{array}{l}\text { When were you diagnosed? } \\
\text { First time } \\
\text { Less than } 5 \text { years } \\
\text { More than } 5 \text { years }\end{array}$ & $\begin{array}{c}4(1.4) \\
129(34.8) \\
224(60.4)\end{array}$ \\
\hline $\begin{array}{l}\text { Where were you first diagnosed as } \\
\text { Primary health care } \\
\text { Physician } \\
\text { Secondary care hospital } \\
\text { Tertiary care hospital } \\
\text { At a pharmacy } \\
\text { Others } \\
\text { I do not know }\end{array}$ & $\begin{array}{l}\text { ion? } \\
\qquad 24(6.5) \\
59(16) \\
84(22) \\
187(50)\end{array}$ \\
\hline $\begin{array}{l}\text { Where do you go for routine follow- } \\
\text { Diagnosis on this visit } \\
\text { This health care } \\
\text { Nearby primary health care clinic } \\
\text { Nearby hospital } \\
\text { Tertiary hospital } \\
\text { I do not do any follow-up }\end{array}$ & $\begin{array}{l}\text { d pressure? } \\
13(3.5) \\
216(58) \\
32(8.6) \\
54(15) \\
22(6) \\
21(6)\end{array}$ \\
\hline $\begin{array}{l}\text { When was your blood pressure last } \\
\text { professional? } \\
\text { Within the past } 12 \text { months } \\
1-5 \text { years ago } \\
\text { Not within the past } 5 \text { years }\end{array}$ & $\begin{array}{l}\text { ealth care } \\
354(95) \\
3(0.8)\end{array}$ \\
\hline $\begin{array}{l}\text { How often do you see your doctor fo } \\
\text { Monthly } \\
\text { Every } 3,4 \text { months } \\
\text { Every } 6 \text { months } \\
\text { Once a year }\end{array}$ & $\begin{array}{c}\text { checkup? } \\
154(40.7) \\
186(50) \\
4(1.1) \\
2(0.5) \\
\end{array}$ \\
\hline $\begin{array}{l}\text { When was your blood cholesterol las } \\
\text { Within the past } 12 \text { months } \\
1-5 \text { years ago } \\
\text { Not within the past } 5 \text { years }\end{array}$ & $\begin{array}{l}203(54) \\
83(22) \\
65(12.5)\end{array}$ \\
\hline $\begin{array}{l}\text { Are you taking medications to lower } \\
\text { Yes } \\
\text { No } \\
\text { Uncertain }\end{array}$ & $\begin{array}{l}\text { sterol level? } \\
204(55) \\
50(16) \\
92(26) \\
\end{array}$ \\
\hline $\begin{array}{l}\text { Has a doctor in the past year ordered } \\
\text { life to lower blood cholesterol level? } \\
\text { Yes } \\
\text { No } \\
\text { Uncertain }\end{array}$ & $\begin{array}{l}\text { our way of } \\
242(65) \\
25(7) \\
92(25)\end{array}$ \\
\hline $\begin{array}{l}\text { Are you currently taking aspirin or e } \\
\text { heart disease or stroke? } \\
\text { yes } \\
\text { No } \\
\text { Uncertain }\end{array}$ & $\begin{array}{l}\text { nt or treat } \\
139(38) \\
87(24) \\
133(56)\end{array}$ \\
\hline $\begin{array}{l}\text { Are you currently using hormone rep } \\
\text { Yes } \\
\text { No } \\
\text { Uncertain }\end{array}$ & $\begin{array}{l}y ? \\
4(1.1) \\
101(27) \\
254(67)\end{array}$ \\
\hline
\end{tabular}

TABle 2: Continued.

\begin{tabular}{lc}
\hline & $N(\%)$ \\
\hline Do you have blood relatives of hypertension? & $214(55)$ \\
Yes & $33(9)$ \\
No & $92(24.8)$ \\
Uncertain & $42(11.7)$ \\
\hline Have you had any complication from your hypertension? & $10(3)$ \\
No & $19(5)$ \\
Renal disease & $10(3)$ \\
Stroke & $131(35)$ \\
Retinopathy & $1(0.3)$ \\
Cardiovascular & $114(30)$ \\
Others & \\
I do not know & $259(70)$ \\
\hline Has a doctor in the past year ordered you to change your way of \\
life to lower your blood pressure? & $18(5)$ \\
Yes & $83(22)$ \\
No &
\end{tabular}

Have you been prescribed any medication to lower your blood pressure?

\begin{tabular}{lc} 
Yes & $348(94)$ \\
No & $1(0.3)$ \\
I do not know & $10(3)$ \\
\hline Do you take all your prescribed medications? & \\
Yes & $272(74)$ \\
No & $1(0.3)$ \\
\hline
\end{tabular}

If you don't take medications regularly, why don't you take them as directed?

I cannot afford the cost $2(0.5)$

My medications are not easily available $3(0.8)$

I do not like to take medications 4 (1.1)

I only take them when I feel that I need them $5(1.3)$

I do not like the side effects of the medication 10 (3)

I prefer alternative medicine $\quad 1(0.3)$

I forget $46(12.4)$

I do not know $1(0.3)$

Not answered $293(79)$

Are you aware of any complication of hypertension?

Yes $286(77)$

No 7 (1.9)

If you are aware, have you been informed by a health care professional?

Yes $278(75)$

No 7 (2)

Have you been told that stroke is related to hypertension?

Yes 285 (77)

No

$7(2)$

disease but could be due to various underlying reasons such as lack of knowledge about HTN, lack of adequate guidance, attitudes regarding treatment of an often asymptomatic condition, and personal health beliefs [26].

\section{Conclusions}

HTN is a major disease condition leading to multiple comorbidities and eventually death. Preventive medicine 
plays a significant role in HTN management. Assessment of KAP towards HTN is essentially required for new development of knowledge-, attitude-, and practice-enhancing programs to reduce the burden of HTN in a country. Our study showed overall satisfactory knowledge about complications of HTN and the importance of adherence to close follow-up. Almost two-thirds of the patients had received advice regarding lifestyle changes resulting in a change of practice. Twenty-five percent of the patients had poor drug compliance, and patients' attitudes towards drug compliance need to be further evaluated by future studies.

\section{Limitations}

The current study was restricted to clinic patients and conducted in a single centre. Considering the fact that factors relating to hypertension looked at in this study may vary demographically in other regions of Sri Lanka, making strong generalizations of the findings, sans multicentre study or a meta-analysis of similar data obtained from two or more regions may have limited accuracy.

\section{Abbreviations}

BP: Blood pressure

HTN: Hypertension

KAP: Knowledge, attitude, and practice.

\section{Data Availability}

The data of the study are available with the authors and are secured with password protection for which only the authors have access to.

\section{Ethical Approval}

Ethical approval was obtained from the Institutional Ethical Review Committee (IERC) of the Faculty of Medicine, University of Peradeniya.

\section{Consent}

Consent for publication was obtained from every participant prior to data collection and from all the authors of the study.

\section{Conflicts of Interest}

The authors declare that they have no conflicts of interest.

\section{Authors' Contributions}

UR conceived the research idea and guided it. UR, NW, and $\mathrm{KB}$ contributed to data collection and literature review. ST and UR analyzed and interpreted the data. KB and UR contributed to drafting of the manuscript. UR guided the other authors in data analysis, interpretation, and correcting the final manuscript. All authors who were involved in the study read and approved the final manuscript.

\section{Acknowledgments}

All authors express their gratitude to all participants who consented to take part in this study. They thank the study participants and staff for their personal time and commitment to this study. The study was self-funded by the authors.

\section{References}

[1] D. Prabakaran, P. Jeemon, S. Ghosh et al., "Prevalence and incidence of hypertension: results from a representative cohort of over 16,000 adults in three cities of South Asia," Indian Heart Journal, vol. 69, no. 4, pp. 434-441, 2017.

[2] H. G. W. A. P. L. Bandara, U. I. Hewarathne, R. M. S. P. Karunarathne et al., "Circadian blood pressure profile and comparison with clinic blood pressure in patients with essential hypertension on treatment; experience from a Teaching Hospital in Sri Lanka," Journal of the Postgraduate Institute of Medicine, vol. 4, no. 2, pp. E58 1-E5811, 2017.

[3] N. W. Jayawardana, W. A. Jayalath, W. M. Madhujith et al., "Aging and obesity are associated with undiagnosed hypertension in a cohort of males in the central province of Sri Lanka: a cross-sectional descriptive study," BMC Cardiovascular Disorders, vol. 17, no. 1, p. 165, 2017.

[4] D. M. P. U. K. Ralapanawa, K. P. Jayawickreme, and E. M. M. Ekanayake, "A case of treatable hypertension: fibromuscular dysplasia of renal arteries," BMC Research Notes, vol. 9, p. 6, 2016.

[5] World Health Organization, Causes of Death 2008, World Health Organization, Geneva, Switzerland, 2008, http://www. who.int/healthinfo/global_burden_disease/cod_2008_ sources_methods.pdf.

[6] C. M. Hales, M. D. Carroll, P. A. Simon, T. Kuo, and C. L. Ogden, "Hypertension prevalence, awareness, treatment, and control among adults aged $\geq 18$ years-Los Angeles county1999-2006 and 2007-2014," MMWR. Morbidity and Mortality Weekly Report, vol. 66, no. 32, pp. 846-849, 2014.

[7] U. Ralapanawa, S. D. Dharmaratne, K. Jayawickreme, and M. Ekanayake, "Epidemiology of newly diagnosed hypertensives in a tertiary care hospital in a developing country," Clinical and Experimental Hypertension, vol. 39, no. 3, pp. 251-256, 2017.

[8] U. Ralapanawa, S. Tennakoon, T. Jayalath, M. Bandara, N. Wickramasurendra, and R. Bandara, "The sociodemography, clinical characteristics and the prevalence of cardiovascular risk factors among a group of elderly hypertensive patients followed up at a tertiary care hospital in Sri Lanka," Journal of Clinical Case Reports and Images, vol. 1, no. 1, pp. 3-15, 2017.

[9] WHO, A Global Brief on Hypertension, WHO, Geneva, Switzerland, 2017, http://www.who.int/cardiovascular_ diseases/publications/global_brief_hypertension/en/.

[10] U. Ralapanawa, N. Nanayakkara, K. P. Jayawickreme, N. Wickramasurendra, and S. Tennakoon, "Analysis and identification of symptoms and risk factors in a cohort of chronic hypertensive patients in a tertiary care hospital in Sri Lanka," Clinical and Experimental Hypertension, vol. 41, no. 5, pp. 409-413, 2018.

[11] H. G. W. A. P. L. Bandara, U. I. Hewarathna, R. M. S. P. Karunarathne et al., "Nocturnal blood pressure patterns in essential hypertensives: an over-looked cardiovascular burden," Ceylon Medical Journal, vol. 63, no. 3, p. 113, 2018. 
[12] S. Mendis, P. Ranasinghe, and B. D. Dharmasena, "Prevalence of hypertension in Sri Lanka-a large population study in the Central Province," The Ceylon Medical Journal, vol. 32, no. 3, pp. 121-127, 1987.

[13] National Survey on Self- Reported Health in Sri Lanka, 2014, https://www.statistics.gov.lk/.../National\%20Survey\%20on\% 20Self-reported\%20Health-2014.

[14] L. Aubert, P. Bovet, J.-P. Gervasoni, A. Rwebogora, B. Waeber, and F. Paccaud, "Knowledge, attitudes, and practices on hypertension in a country in epidemiological transition," Hypertension, vol. 31, no. 5, pp. 1136-1145, 1998.

[15] S. P. Bhatt, T. K. Luqman-Arafath, and R. Guleria, "Non pharmacological management of hypertension," Indian Journal of Medical Sciences, vol. 61, no. 11, pp. 616-624, 2007.

[16] S. Tesema, B. Disasa, S. Kebamo, and E. Kadi, "Knowledge, attitude and practice regarding lifestyle modification of hypertensive patients at Jimma University Specialized Hospital, Ethiopia," Primary Healthcare: Open Access, vol. 6, no. 1, p. 218, 2016.

[17] F. Sabouhi, S. Babaee, H. Naji, and A. H. Zadeh, "Knowledge, awareness, attitudes and practice about hypertension in hypertensive patients referring to public health care centers in Khoor \& Biabanak," Iranian Journal of Nursing and Midwifery Research, vol. 16, no. 1, pp. 34-40, 2011.

[18] E. L. Knight, R. L. Bohn, P. S. Wang, R. J. Glynn, H. Mogun, and J. Avorn, "Predictors of uncontrolled hypertension in ambulatory patients," Hypertension, vol. 38, no. 4, pp. 809-814, 2001.

[19] I. Balazovjech and P. Hnilica, "Compliance with antihypertensive treatment in consultation rooms for hypertensive patients," Journal of Human Hypertension, vol. 7, no. 6, pp. 581-583, 1993.

[20] H. Mahajan, Y. Kazi, B. Sharma, and G. D. Velhal, "Assessment of KAP, risk factors and associated co-morbidities in hypertensive patients," IOSR Journal of Dental and Medical Sciences, vol. 1, no. 2, pp. 6-14, 2012.

[21] C. Chijioke, R. Anakwue, T. Okolo et al., "Awareness, treatment, and control of hypertension in primary health care and secondary referral medical outpatient clinic settings at Enugu, Southeast Nigeria," International Journal of Hypertension, vol. 2016, Article ID 5628453, 5 pages, 2015.

[22] WHO, Raised Blood Pressure, WHO, Geneva, Switzerland, 2017, http://www.who.int/gho/ncd/risk_factors/blood_ pressure_prevalence_text/en.

[23] B. Davies and S. Saltmarsh, "Gender economies: literacy and the gendered production of neo-liberal subjectivities," Gender and Education, vol. 19, no. 1, pp. 1-20, 2007.

[24] C. Delpachithra and S. Jayasinghe, "Overcrowding and "floor" patients in state hospitals: institutions can make a difference," Ceylon Medical Journal, vol. 46, no. 2, p. 58, 2017.

[25] M. A. Oto, O. Ergene, L. Tokgözoğlu et al., "Impact of a mass media campaign to increase public awareness of hypertension," Archives of the Turkish Society of Cardiology, vol. 39, no. 5, pp. 355-364, 2011.

[26] C. O. Amira and N. U. Okubadejo, "Factors influencing noncompliance with anti-hypertensive drug therapy in Nigerians," The Nigerian Postgraduate Medical Journal, vol. 14, no. 4, pp. 325-329, 2007. 